Research Article

\title{
The Optimal PPP Model of Emergency Rescue Service
}

\author{
Guangxi Cao $\mathbb{D}^{1,2,3}$ and Ling Zhou $\mathbb{D}^{1}$ \\ ${ }^{1}$ School of Management Science and Engineering, Nanjing University of Information Science \& Technology, Ningliu Road 219, \\ Nanjing, Jiangsu 210044, China \\ ${ }^{2}$ Binjiang College, Nanjing University of Information Science \& Technology, Xishan Road 333, Wuxi, Jiangsu 214105, China \\ ${ }^{3}$ Collaborative Innovation Center on Forecast and Evaluation of Meteorological Disasters, \\ Nanjing University of Information Science \&Technology, Ningliu Road 219, Nanjing, Jiangsu 210044, China
}

Correspondence should be addressed to Guangxi Cao; caoguangxi@nuist.edu.cn

Received 7 July 2020; Revised 27 October 2020; Accepted 19 December 2020; Published 5 January 2021

Academic Editor: Aihua Li

Copyright (c) 2021 Guangxi Cao and Ling Zhou. This is an open access article distributed under the Creative Commons Attribution License, which permits unrestricted use, distribution, and reproduction in any medium, provided the original work is properly cited.

\begin{abstract}
Based on the analysis of the shortage of emergency rescue services and the supervision of public-private-partnership (PPP) projects, this paper explores the rent-seeking game predicament and establishes a three-player rent-seeking game model among government regulators, private enterprises, and government agents in the bidding operation of PPP projects by learning from Stackelberg game theory. Through the numerical simulation analysis, this paper explores the impact of the relevant variables on the model results, which can lead to the following conclusions: the emphasis on government regulators changes due to rentseeking cost changes; when the success rate of verification is high, government regulators can take supervision randomly. Inversely, supervision channels should be broadened when the supervision fails. When the punishment on government agents and private enterprises is great, relaxing supervision may be appropriate. This study proposes the relevant policy recommendations for government regulators to improve their work.
\end{abstract}

\section{Introduction}

From the floods in 1998 and the snowstorms in the south in 2008 to the heavy traffic accidents in the Shenhai Expressway and the "812" explosion in Tianjin in recent years, all kinds of safety emergencies in our country are in a high incidence. The density and wide distribution of the population make the casualties and property losses huge in the case of public security incidents, such as natural disasters. Thus, establishing a sound emergency rescue service system is an important measure to deal with the losses caused by these major disasters and accidents. China's emergency rescue service is still in its infancy, and many practical problems exist, such as the shortage of funds and inadequate rescue work in government finance and the construction of rescue teams, making the fulfilment of the increasing public demand difficult. Therefore, the government should continue to respond to the call of the 18th National Congress, innovate the rescue service model, and increase the purchase of services from social forces. Private enterprises have strong professional skills and obvious advantages in emergency rescue. Letting them join in emergency rescue services can realize perfect cooperation with government organizations to minimize losses. However, in government-enterprise cooperation, especially in emergency rescue services, the interests of the government and enterprises are not the same. The government seeks to maximize public interests, whereas private enterprises pursue maximizing profitability and minimizing risk. At the same time, the government is often done through agent bidding service. Therefore, research on emergency rescue service optimal PPP mode has strong practical significance in exploring the government 
regulators, private enterprises, and government agents of the tripartite game.

1.1. Study on Emergency Rescue Services. Based on the analysis of documents and interviews with state-owned and voluntary organizations participating in emergency rescue, Nivolianitou and Synodinou [1] determined that the financial assistance provided by national institutions cannot satisfy the needs and believed that the preferred partner is important for a successful emergency rescue. Cordero-Reyes et al. [2] also stated in their study on the disaster management plan of academic institutions after the earthquake in Ecuador that having a team responsible for managing continuous emergency rescue can have a positive impact on a number of areas. Cole et al. [3] studied the extent to which predisaster planning and postdisaster assistance can help enterprises recover from the negative effects of natural disasters, and the results show that postdisaster assistance from local banks and trading partners has a positive impact on postdisaster sales, but the direct cash payments from the government do not seem to have a significant impact. Paul et al. [4] by interviewing 302 earthquake survivors in Nepal established an additive composite index score to measure the governmental and nongovernmental organizations and other organizations in the emergency rescue in Nepal; the results indicate that, regardless of the aspects of emergency rescue speed or the provision of emergency material, the contribution of a nongovernmental organization to the emergency rescue is above that of a governmental organization. Cook et al. [5] mentioned in the study of international humanitarian assistance for the Nepal earthquake in 2015 that, as a donor and direct service provider of emergency relief services, private sector companies are increasingly involved in disaster response, and the collaboration with aid agencies' support staff has improved relief efficiency.

Foreign scholars' research on emergency rescue is mostly limited to the comparison between governmental and nongovernmental organizations. Although Pakistan [6], Finland, [7] and other countries have demonstrated the advantages of cooperating with the private enterprises in the emergency medical services, only few studies focus on private enterprises' participation in emergency rescue services. Chinese scholars have conducted plenty of research on this aspect. Certain research shows that various private rescue enterprises emerge not only to improve the country rescue level but also to fill many gaps in the emergency rescue field [8]. Ali et al. [6] indicated that establishing a socialized emergency rescue service system is necessary and proposed practical suggestions for the construction of a rescue service system by analyzing its purpose and summarizing rescue work. Shan [9] believed that the emergency industry has a good development prospect and proposed a government-led enterprise-oriented target model. Zhang et al. [10] investigated the socialized rescue service system of mountaineering in China and proposed relevant socialized rescue suggestions by referring to the effective rescue experience of other countries and regions. Chen [11] used
Daya Bay petrochemical area as an example to explore the emergency rescue service mode of hazardous chemicals and pointed out that the mode of "government-enterprise assistance" has a certain reference value. Jiang [12] analyzed emergency rescue cases in various parts of China and pointed out that the Chinese government plays a leading role in purchasing disaster shelters and emergency rescue services, actively exploring the feasibility of innovating new service models and introducing the PPP model into emergency service construction. The government can use the professional services of enterprises to improve disaster relief capabilities. At the same time, enterprises can use the government's emergency management experience to improve business management skills [13]. Therefore, Zhang and Tong [14] stated that the multiparticipation of government agencies, private sectors, and social organizations in emergency management is an inevitable trend.

\subsection{Research on PPP Project Supervision. Zhao [15] proposed} suggestions for evading and managing risks on the basis of failed PPP projects. Certain risks linked to governmental actions, such as government corruption (Chan et al. [16]), default or intervention (Ke et al. [17]), and project approval and permit delay ( $\mathrm{Ng}$ and Loosemore [18]), may incur losses of private capital involved in PPP projects. Moreover, imperfect supervision systems (Xu et al. [19]) or laws and regulations may cause some problems during project implementation. Zhang et al. [20] employed a decisionmaking trial and evaluation laboratory method to analyze the five major risk factors in Sponge City PPP projects. Among them, an inadequate supervision system, government intervention, immature law, and regulations are the key risk factors related to the government. Therefore, the government should do a good job of supervising PPP projects and strengthening planning guidance. Lu [21] analyzed four ways of PPP operation on the basis of typical cases and proposed strategies to promote PPP, such as strengthening whole-process supervision through the reasonable use of different competitive procurement methods. On the basis of domestic foreign experience, Wang and Liu [22] analyzed the three aspects of government regulation, access, and performance supervision and proposed that two kinds of publicity (public transparency and public bidding) are the best ways to implement effective supervision. Chen et al. [23] studied the game model of PPP supervision and rent-seeking, pointed out the game dilemma existing in the cooperation between government and enterprise, and finally proposed suggestions from the aspects of the legal system, competition mechanism, and information disclosure. Chen [24] believed that independent and professional supervision agencies must be introduced to supervise the PPP model of infrastructure to realize the separation of government functions. He and Wang [25] studied the PPP project asymmetric game model under the incomplete information and believed that game players can continue to adjust their strategy until the model tends to gain equilibrium stability or shock state by analyzing different conditions of the steady state. They also made suggestions from two aspects of private 
companies and government departments to guarantee the successful operations of the PPP project.

For the emergency rescue services in the enterprise cooperation, the government aims to maximize public benefit, whereas rational private enterprises pursue maximizing profitability and minimizing risk. To prevent private enterprises from bribing government agents to obtain this enterprise project or other economic resources or prevent government agents from accepting all kinds of private enterprises' "rent-seeking," government regulators should strengthen the regulation of the PPP project. A three-player game study on government and enterprise rent-seeking in emergency rescue service does not exist. In this research, in combination with emergency rescue service characteristics on the basis of urgency, complexity, and diversity, we first explore the various variables to the influence degree of supervision and rent-seeking probabilities by analyzing the data simulation of the tripartite game model of government agents, private enterprises, and government regulators. We then provide the relevant policy recommendations and the guidance of government supervision departments to do a good job of supervision and ensure the maximization of public interest.

\section{PPP Rent-Seeking Game Model}

2.1. Basic Model. The rent-seeking behavior among government agents, private enterprises, and the supervision of supervision departments on the rent-seeking behavior constitute a three-party game. The main participants are government agents, private enterprises, and supervision departments. Private enterprises are bidder operators that may contract PPP projects in violation of regulations. Government agents are the governors who negotiate with enterprises and have the right to decide on PPP projects. As government agents likely seek corporate rent for personal gain, resulting in loss of government and public interest, the introduction of third-party supervision departments may exist in reality to regulate both parties. This article assumes that the regulator is upright, does not accept any form of rent-seeking, carefully performs the duty of supervising government agents and private enterprises, and imposes punishment on violations. In practice, not every PPP project exists with rent-seeking behavior, and the government does not likely take many resources to monitor all aspects of the PPP project progress due to the incompleteness of information acquisition, regulators, and rentseeking partners, where every behavior has a certain probability. Therefore, this study discusses the situation of the three-party mixed strategy Nash equilibrium of supervision departments, government agents, and private enterprises.

2.1.1. Related Variable Setting. We set the following related variables.

The utility is represented by $U(0 \leq U \leq 1)$, and the game participants are pursuing the greatest utility.
The expected value of the PPP project for an emergency rescue service in the plan is estimated to be $S$, and the private company wins the project at the price of $Y$, and $Y<S, Y>0$.

The diversity of emergency types leads to the complexity of emergency rescue services. Therefore, the success rate of project use $m(0 \leq m \leq 1)$ indicates the risks faced by private enterprises in the process of emergency rescue services.

If the rent-seeking behavior occurs in the private enterprise, then the success rate of the project increases $n(0 \leq n \leq 1-m)$. At this time, the rent-seeking cost is $C$, and the rent-seeking private enterprise income is $(m+n) S-Y-C$. Generally, $Y+C \leq(m+n) S$ is established, and the final income obtained by private enterprises in choosing rent-seeking cooperation must be not less than the income without rent-seeking. Otherwise, rational private enterprises can choose to participate normally.

The income of a government agent comprises two parts: one is fixed salary $V$, and the other is additional income $C$ (i.e., the rent of a private enterprise).

Social benefits brought by emergency rescue projects are expressed as E. Given the rapid outbreak of emergencies, quickly responding and organizing an emergency rescue is necessary to reduce social losses. Social benefits are affected by the time of rescue, which shows the characteristic of decreasing with the extension of time. Considering the positive externality of social benefits brought by the PPP project of emergency rescue service, assume that the social benefits when no illegal operation of government and enterprise exist are $E(E \geq 0)$, and the social benefits when rentseeking occurs decrease $A(A \geq 0)$. Moreover, to ensure the necessity of conducting the PPP project of emergency rescue service, $E \geq A$ constant is established.

The supervision cost of the third-party supervision department is $K$. Private companies and government agents will be fined if evidence of rent-seeking is found, $M$ times the fine on the former's maximum return $[(m+n) S-Y]$, and $N$ times the fine for rent-seeking proceed $C$ from government agents. The total fine is expressed by $F$, where $F=N C+M[(m+n) S-Y]$. To ensure that the supervision probability is within the effective value range, a penalty greater than the supervision cost must be imposed, which is $F \geq K$, for ensuring the enthusiasm of supervision departments.

The probability that supervision departments adopt a supervision strategy is $p(0 \leq p \leq 1)$, and the probability of private sector and government agents conducting rentseeking activities is $q(0 \leq q \leq 1)$.

The probability that supervision departments conduct an audit and verify the success is $r(0 \leq r \leq 1)$. When supervision departments supervise rent-seeking activities, smoothly finding the evidence every time is not guaranteed.

2.1.2. Game Model Assumptions. Given that different behavior choices exist for game participants, five situations have emerged.

Situation 1: the government is seeking rent, and supervision departments are not supervising; the 
revenues of government agents, private enterprises, and supervision authorities are, respectively,

$$
\begin{aligned}
& V+C, \\
& (m+n) S-Y-C, \\
& -[(m+n) S-Y]+(m+n)(E-A) .
\end{aligned}
$$

Situation 2: the government and enterprise are seeking rent, and supervision departments try and fail to supervise; the revenues are as follows:

$$
\begin{aligned}
& V+C, \\
& (m+n) S-Y-C, \\
& -[(m+n) S-Y]-K+(m+n)(E-A) .
\end{aligned}
$$

Situation 3: the government and enterprise are seeking rent, but supervision departments regulate successfully; the revenues are as follows:

$$
\begin{aligned}
& C-N C, \\
& {[(m+n) S-Y]-M[(m+n) S-Y]-C,} \\
& F-K+V+(m+n)(E-A) .
\end{aligned}
$$

Situation 4: the government and enterprise are not seeking rent, and supervision departments are not supervising; the revenues are as follows: $V, 0, m E$.

Situation 5: the government and enterprise are not seeking rent, but supervision departments are supervising; the revenues are, respectively, $V, 0, m E-K$.

We organize the income matrix of government agents, private enterprises, and government supervision departments. See Table 1.

\subsection{Model Solution}

2.2.1. Optimal Rent-Seeking Probability. When no difference exists between the supervision revenue and the nonsupervision income of supervision authorities, that is, when the game model is in equilibrium, the optimal rent-seeking probability of the government and enterprises can be obtained as follows:

supervision: $U_{1}=q\{(r M-1+r)[(m+n) S-Y]+r N C+r V+(m+n)(E-A)\}+m E-K-m E q$,

nonsupervision: $U_{2}=q\{(m+n)(E-A)-[(m+n) S-Y]\}+m E-m E q$,

optimal rent - seeking probability: $q^{*}=\frac{K}{r\{(M+1)[(m+n) S-Y)]+N C+V\}}$.

2.2.2. Optimal Supervision Probability. The optimal supervision probability for supervision departments is divided into two cases.

Scenario 1. When the model of the expected income equality between government agents choosing rent-seeking and non-rent-seeking is in equilibrium:

$$
\begin{aligned}
& \text { rent }- \text { seeking: } U_{3}=-r(N C+V) p \\
& +C+V \text {, } \\
& \text { non }- \text { rent }- \text { seeking: } U_{4}=V \text {, }
\end{aligned}
$$

optimal supervision probability: $p_{z}^{*}=\frac{C}{r(C N+V)}$.
Scenario 2. When the model of the expected income equality between private enterprises choosing rent-seeking and non-rent-seeking is in equilibrium:

$$
\text { rent - seeking: } \begin{aligned}
U_{5}= & -r M p[(m+n) S-Y] \\
& +(m+n) S-Y-C,
\end{aligned}
$$

non - rent - seeking: $U_{6}=0$,

optimal supervision probability: $p_{s}^{*}=\frac{(m+n) S-Y-C}{r * M[(m+n) S-Y]}$.

Therefore, the Nash equilibrium of the mixed strategy of the three-party game model established by Scenarios 1 and 2 is as follows:

$$
\begin{aligned}
& {\left[q^{*}=\frac{K}{r\{(M+1)[(m+n) S-Y)]+N C+V\}}, p^{*}=\frac{C}{r(C N+V)}\right],} \\
& {\left[q^{*}=\frac{K}{r\{(M+1)[(m+n) S-Y)]+N C+V\}}, p^{*}=\frac{[(m+n) S-Y-C]}{[(m+n) S-Y] r M}\right] .}
\end{aligned}
$$


TABLE 1: Income matrix of government agents, private enterprises, and government supervision departments.

\begin{tabular}{|c|c|c|c|c|}
\hline & \multicolumn{4}{|c|}{ Supervision $p$} \\
\hline & & Success $r$ & Failure $(1-r)$ & Nonsupervision $(1-p)$ \\
\hline \multirow[b]{2}{*}{ Rent-seeking $q$} & Government agents & $-(N-1) C$ & $V+C$ & $V+C$ \\
\hline & Private enterprises & $\begin{array}{l}{[(m+n) S-Y]-} \\
M[(m+n) S-Y]-C\end{array}$ & $(m+n) S-Y-C$ & $(m+n) S-Y-C$ \\
\hline Supervision departments & $F-K+V+(m+n)(E-A)$ & $\begin{array}{l}-[(m+n) S-Y]- \\
K+(m+n)(E-A)\end{array}$ & $\begin{array}{l}-[(m+n) S-Y] \\
+(m+n)(E-A)\end{array}$ & \\
\hline \multirow{3}{*}{ No rent-seeking $(1-q)$} & Government agents & $V$ & $V$ & $V$ \\
\hline & Private enterprises & 0 & 0 & 0 \\
\hline & Supervision departments & $m E-K$ & $m E-K$ & $m E$ \\
\hline
\end{tabular}

2.3. Data Simulation Analysis. To explore the influence of each variable on the optimal rent-seeking probability and the optimal supervision probability, values must be assigned to each parameter in the model. Given that the data of private enterprises participating in the PPP project of emergency rescue in China are unavailable, this study combines the actual development of China's industrial industry to simulate each parameter, and the data source is "China Industry Statistical Yearbook 2015-Large and Medium-Sized Private Industrial Enterprises" (the annual data used to support the findings of this study have been deposited in 《China Industry Statistical Yearbook》 (ISBN: 978-7-5037-7673-1)).

We refer to Duan [26] for the basic assignment of each parameter in the model (The expected value of project Stakes the means of the proportion of the operating profit of large and medium-sized private industrial enterprises. $Y$ uses the proportion of the main business income of private industrial enterprises. The rent-seeking cost $C$ of private enterprises adopts the proportion of tax in administrative expenses. Government agent wage $V$ refers to rent-seeking cost. Social benefit $E$ adopts the ratio of the total profits of state-owned industrial enterprises to the total profits of private industrial enterprises. When seeking rent, the reduction of social benefit $A$ adopts the ratio of loss amount to industry profit times expected revenue. No suitable reference for supervision cost $K$ has been found. Reduction of social benefits is adapted as supervision cost. Punishment intensity $M$ and $N$ supervision department imposes on government and enterprises adopt the proportion of VAT payable by private industrial enterprises in total profits. The success rate of project $m$ adopts $-==$ the proportion of the industry with investment income and loss in the total industry. The success rate of supervision $r$ has no suitable reference value and adopts the value of project success rate. The variation of project success rate $n$ adopts the percentage of industries with losses of more than 1 billion RMB.): expected value of the project $S=0.554, Y=0.336$, $C=0.057, \quad V=0.057, \quad K=0.02, \quad M=0.440, \quad N=0.440$, $F=0.06, m=0.4, r=0.4, n=0.35, E=0.574$, and $A=0.02$. Under this assignment, optimal rent-seeking probability $q^{*}=$ 0.254 is obtained. The optimal regulation probability is greater than 1, indicating that no Nash equilibrium exists; namely, whether regulators choose regulation, the private enterprise and the government agent of rent-seeking yields are greater than those of the non-rent-seeking income. Therefore, on the basis of the assignment below, change the value of the research parameter to observe its change for optimal rentseeking probability or optimal supervision probability while keeping other parameters constant.

Object 1: the influence of rent-seeking cost $C$ and rentseeking maximum profit $(m+n) S-Y$ on $q^{*}$ and $p^{*}$

Assume that $t=0.75 S-Y$ and constraint conditions are distributed mainly between $(0,1)$, formula $t \geq C \geq 0$, and $F=0.0251+0.44 t>0.02$ are established

Optimal rent-seeking probability: $q^{*}=(1 / 28.8$ $* t+8.8 C+1.14)$, optimal supervision probability $p_{z}^{*}=(C / 0.176 C+0.02)$, and $p_{s}^{*}=(t-C / 0.176 t)$

In Figure 1, the horizontal axis represents the maximum rent-seeking benefits and costs of private enterprises, whereas the vertical axis represents the optimal rentseeking probability. As seen from Figure 1, with the increase in rent-seeking cost and maximum rent-seeking revenue, the surface shows a trend of decline, and the optimal rent-seeking probability decreases accordingly and eventually tends to become 0 . Moreover, the maximum rent-seeking revenue has a great influence on the optimal rent-seeking probability. When the expected profit that private enterprises may obtain is large or the rent-seeking cost is large, supervision departments can relax the regulation because the rent-seeking probability is low, and the profit from supervision is less than that from nonsupervision. However, when the expected revenue of private enterprises is relatively small, they seek rent from government agents to improve the success rate of the project and guarantee the revenue. In this case, the rentseeking probability is relatively high, and supervision departments should adopt a supervision strategy.

In Figure 2, the horizontal axis represents the rentseeking cost, whereas the vertical axis represents optimal supervision probability $p_{z}^{*}$. As seen from Figure 2 , with the increase in rent-seeking cost, the curve shows an upward trend, and the probability of optimal supervision increases accordingly. When the interests of government agents are maximized, the high rent-seeking cost is a temptation for 


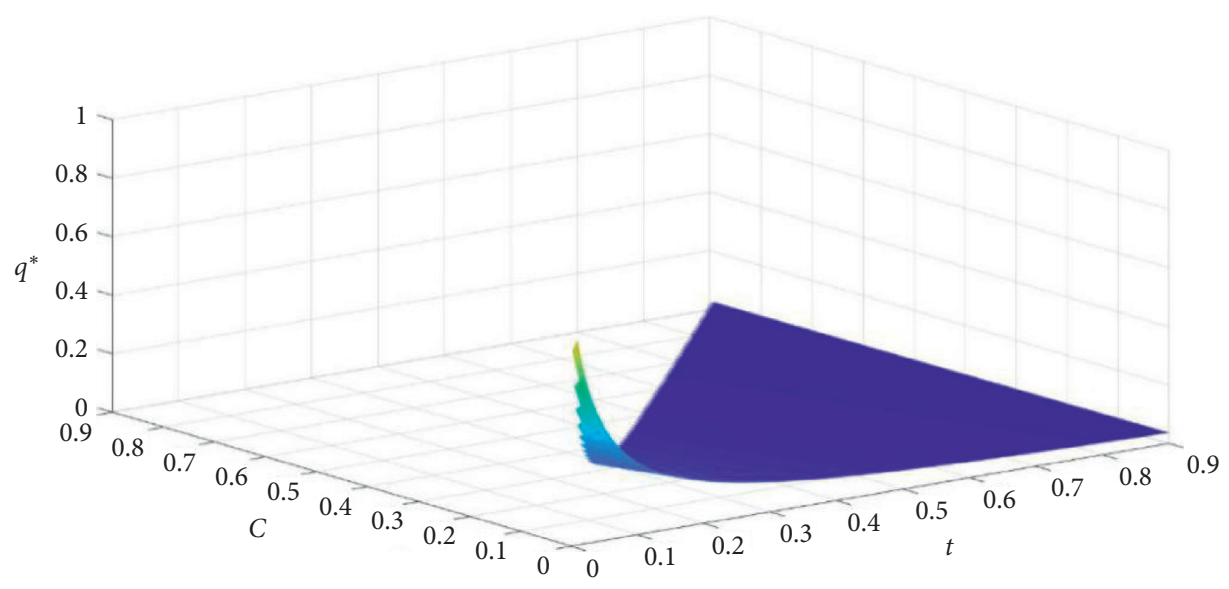

FIgURE 1: Simulation diagram of the influence of maximum rent-seeking revenue and rent-seeking cost on the optimal rent-seeking probability $q^{*}$ of private enterprises.

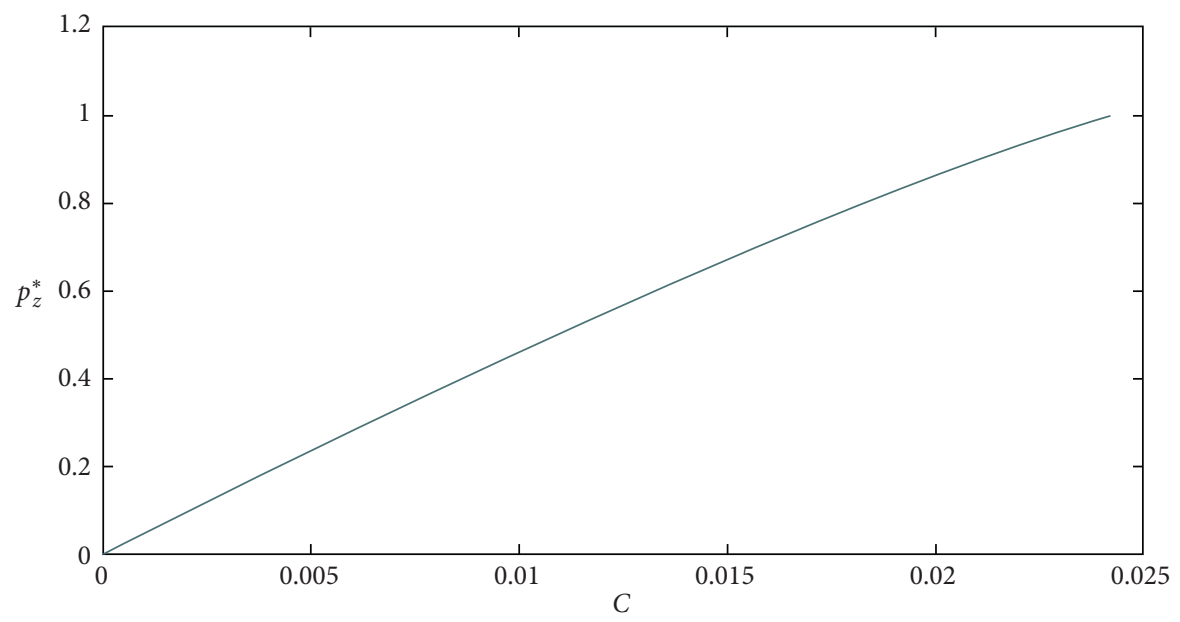

FIgURE 2: Simulation diagram of the impact of rent-seeking cost on optimal supervision probability $p_{z}^{*}$.

government agents. To gain extra profits for individuals, government agents can take risks to accept the rent-seeking behavior of private enterprises. Only by improving the probability of supervision can supervision departments effectively prevent rent-seeking behavior.

In Figure 3, the horizontal axis represents the maximum rent-seeking benefits and rent-seeking costs of private enterprises, whereas the vertical axis represents optimal supervision probability $p_{s}^{*}$. When the interests of private enterprises are maximized, the optimal supervision probability is affected by rent-seeking cost and rent-seeking maximum profit. As illustrated in Figure 3, with the increase of rent-seeking cost and maximum benefit, the curve generally presents an upward trend, and the probability of optimal supervision increases accordingly. When the maximum profit and rent-seeking cost are high, the probability of optimal supervision is relatively large. In this case, the optimal strategy of private enterprises is not to seek rent.

Conclusively, when rent-seeking cost $C$ and maximum benefit $(m+n) S-Y$ increase, the probability of optimal rent-seeking decreases, and the probability of optimal supervision increases. The optimal strategy of the three parties is not rent-seeking and not supervision. If a rent-seeking behavior exists when the rent-seeking cost is large, then the supervision focus of supervision departments is the government agents, whereas when the rent-seeking maximum profit is large, the supervision focus is the private enterprises.

Object 2: influence of project success rate $m$ and change in success rate $n$ on $q^{*}$ and $p^{*}$.

Constraint conditions: $q^{*}$ and $p^{*}$ are distributed between $(0,1), 0 \leq m \leq 1,0.709386 \leq m+n \leq 1$, and $F=$ $0.24376(m+n)-0.12274>0.02$ are constant.

Optimal rent-seeking probability: $q^{*}=(1 / 15$. $9552(m+n)-8.0348)$; optimal supervision probability $p_{s}^{*}=9.368236-(0.057 / 0.097504(m+n)-0.059136)$.

In Figure 4, the horizontal axis represents the success rate of the project and the change in the project success rate, whereas the vertical axis represents optimal rent-seeking probability $q^{*}$. As seen from Figure 4 , as the project success rate and its variation increase, the surface presents a trend of decline, and the optimal rent-seeking probability decreases accordingly. To ensure that the final benefit of choosing rent- 


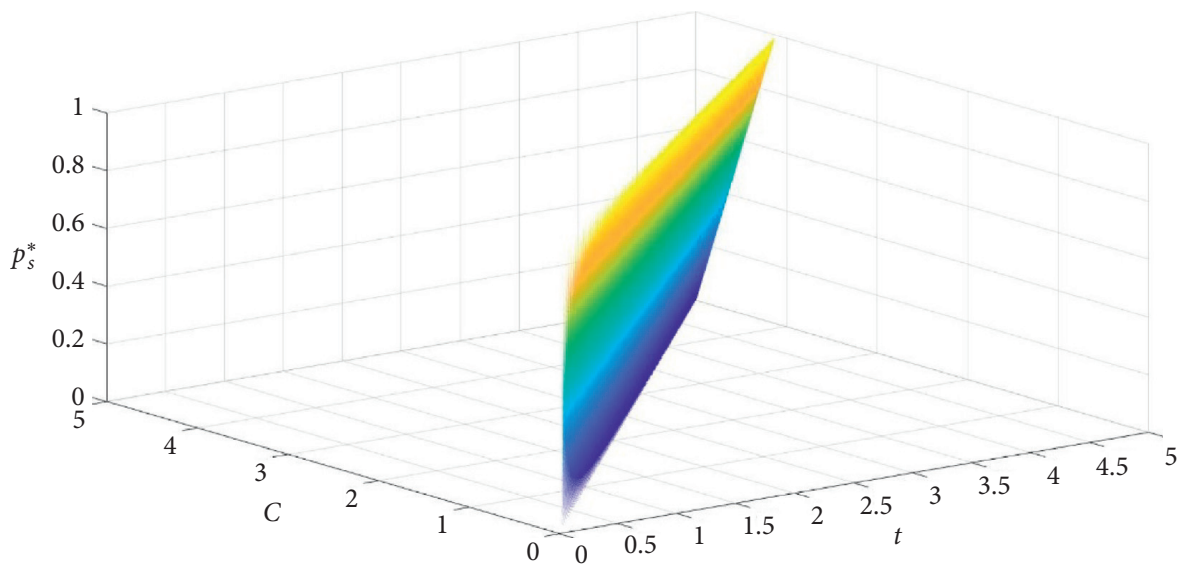

FIGURE 3: Simulation diagram of the influence of private enterprises' maximum rent-seeking profit and rent-seeking cost on optimal supervision probability $p_{s}^{*}$.

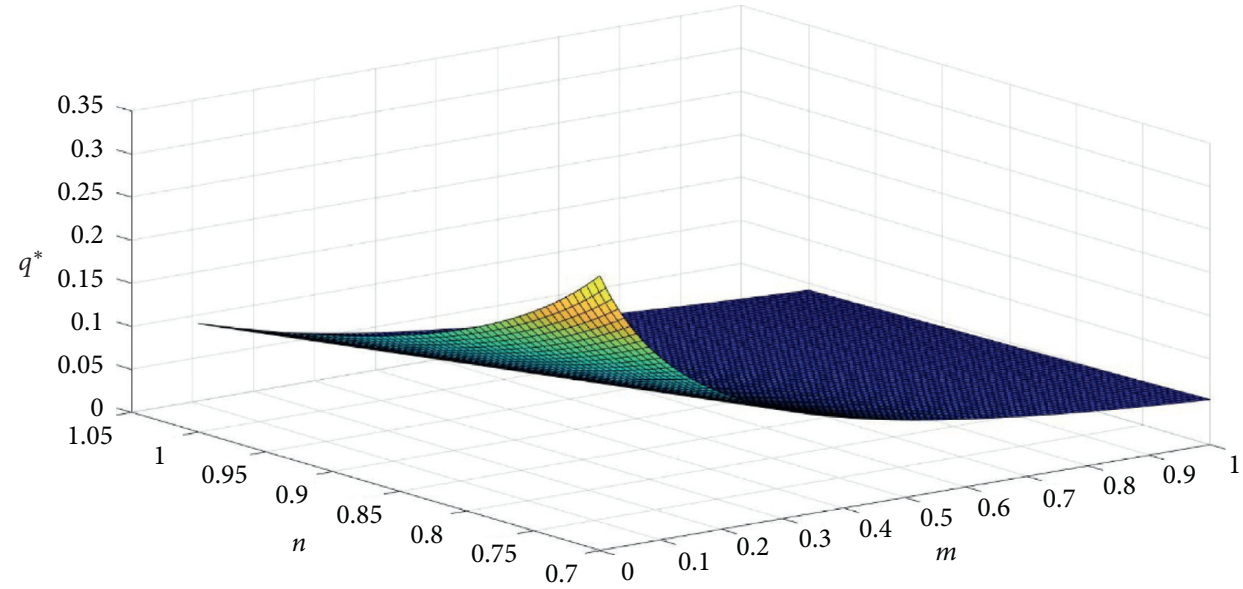

FIGURE 4: Simulation diagram of the influence of project success rate and variation of project success rate on optimal rent-seeking probability $q^{*}$.

seeking cooperation is greater than that of not seeking rent, private enterprises must ensure the overall project success rate to cope with the complexity of emergency rescue missions. If the project success rate is relatively small, then private enterprises can choose to seek rent to improve the success rate and guarantee profits.

In Figure 5, the horizontal axis represents the project success rate and the change in the project success rate, whereas the vertical axis represents optimal supervision probability $p_{s}^{*}$. As seen from Figure 5 , as project success rate and its variation increase, the surface presents a rising trend, and the probability of optimal supervision increases accordingly. When private enterprises choose to seek rent to improve the success rate and ensure profits, the probability of the optimal supervision of supervision departments increases, and supervision measures must be taken. The government can also take measures to help enterprises reduce risks and ensure the successful operation of the project.

Object 3: influence of verification success rate $r$ on $q^{*}$ and $p^{*}$
Constraint conditions: $q^{*}$ and $p^{*}$ are distributed between $(0,1), 0 \leq r \leq 1$

Optimal rent-seeking probability: $q^{*}=(1 / 0.1018 r)$; optimal supervision probability $p_{z}^{*}=(1 / 0.6944 r)$

In Figure 6, the horizontal axis represents the verification success rate, whereas the vertical axis represents the optimal supervision probability or the optimal rent-seeking probability under different verification success rates. As illustrated in Figure 6, when the verification success rate increases gradually, the optimal rent-seeking probability and the optimal supervision probability decrease gradually, and they have a great influence on the optimal supervision probability.

The expected incomes of government agents who conduct rent-seeking activities and those who do not are as follows: rent-seeking: $U_{3}=-0.0821 r p+0.114$; no rentseeking: $U_{4}=0.057$. When the success rate of verification is relatively small, only when the probability of supervision is increased does the rent-seeking income of government 


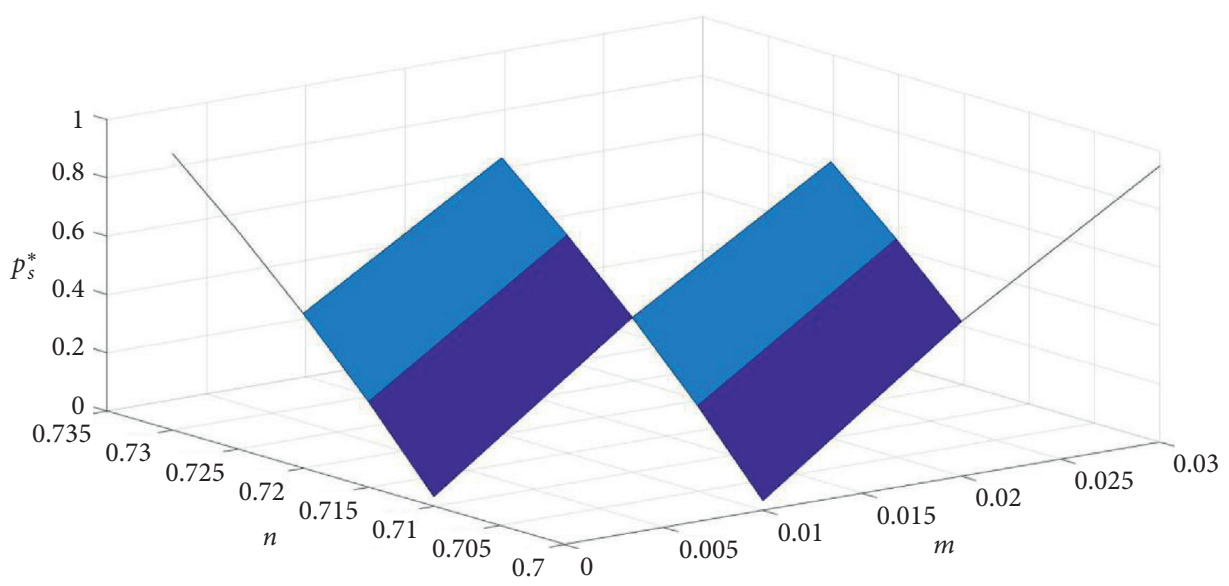

FIGURE 5: Simulation diagram of the influence of project success rate and the variation of project success rate $p_{s}^{*}$ on optimal supervision probability.

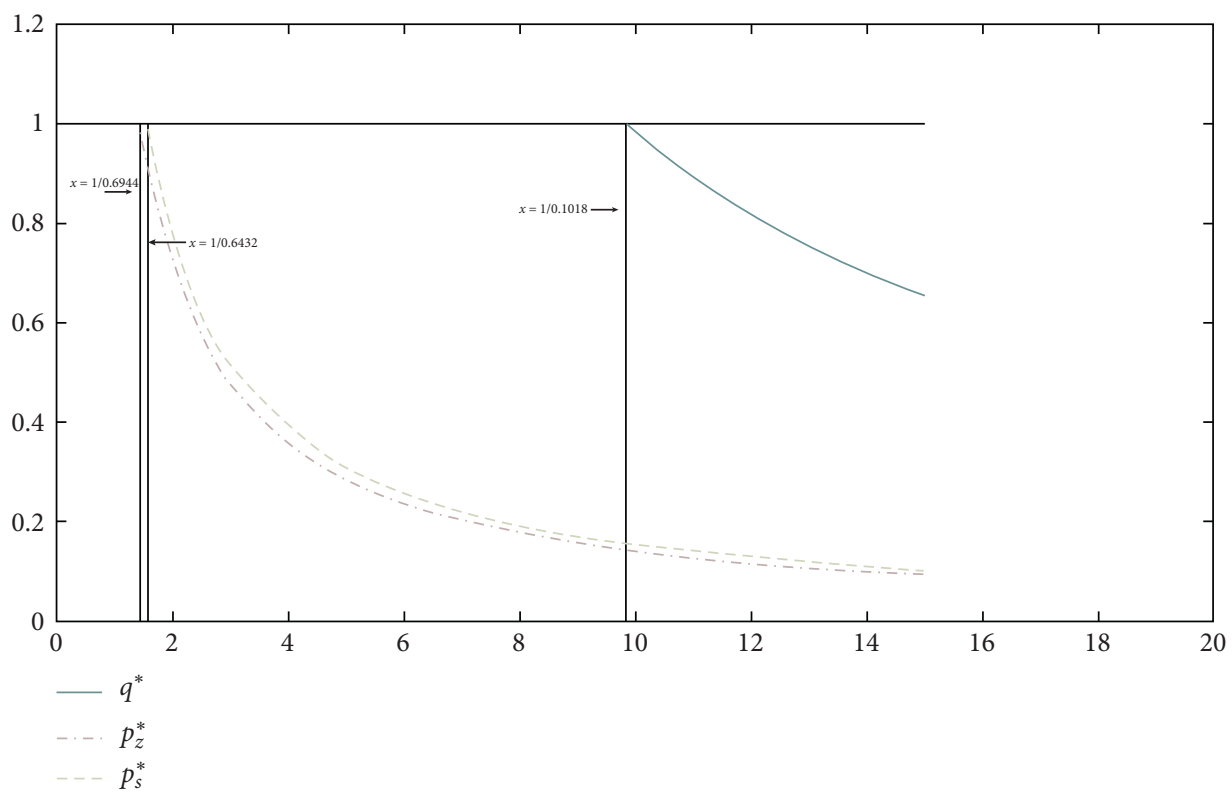

FIGURE 6: Simulation diagram of the impact of verification success rate on optimal rent-seeking probability and optimal supervision probability.

agents become lower than the non-rent-seeking income, and government agents do not violate the rules. However, if the supervision probability remains unchanged, then the rent-seeking income of government agents under high verification success rate is smaller than those under low verification success rate. Similarly, the rent-seeking incomes of private enterprises with high verification success rate are far less than those with low verification success rate. Therefore, improving the verification success rate can effectively reduce the rent-seeking behavior, and regulators can appropriately deregulate. The verification success rate of 0 indicates that supervision departments have failed. At this time, we should improve the supervision method, and the public and online media should actively participate in it.
Object 4: influence of punishment intensity $N$ on government agents on $q^{*}$ and $p^{*}$

Constraint conditions: $q^{*}$ and $p^{*}$ are distributed between $(0,1), N>1.5$, and $F=0.057 N+0.03498>0.02$ are set up

Optimal rent-seeking probability: $q^{*}=(1 / 3.4296 t$ $+n 1.14 q N)$; optimal supervision probability $p_{z}^{*}=(5 / 2 N+2)$

According to Figure 7, under this hypothesis, when punishment intensity $N$ for government agents gradually increases, the optimal probability of supervision $p_{z}^{*}$ and the optimal probability of rent-seeking $q^{*}$ show a decreasing trend. As $\left(p_{z}^{*}\right)^{\prime}=\left(-5 / 2(N+1)^{2}\right), \quad\left(q^{*}\right)^{\prime}=(-1.14 /$ $\left.(1.14 N+3.4296)^{2}\right)$, and $\left|-5 / 2(N+1)^{2}\right|>\quad \mid-1.14 /$ 
$(1.14 N+3.4296)^{2} \mid$, the punishment intensity for government agents has an obvious impact on the optimal supervision probability. Increasing the punishment intensity can effectively reduce the probability of optimal supervision when the interests of government agents are maximized.

Similarly, increasing punishment intensity $M$ for private enterprises can reduce the optimal rent-seeking probability and optimal supervision probability, and the influence on the optimal supervision probability becomes obvious. That is, increasing punishment intensity $M$ for private enterprises can effectively reduce the optimal supervision probability when the interests of private enterprises are maximized, and supervision departments can relax the supervision appropriately.

Object 5: discussion of the influence of government agents' salary $V$ on $q^{*}$ and $p^{*}$

Constraint conditions: $q^{*}$ and $p^{*}$ are mainly distributed between $(0,1)$

Optimal rent-seeking probability: $q^{*}=(1 / 2.79$ $12+20 \mathrm{~V}) ; \quad$ optimal supervision probability $p_{z}^{*}=(0.57 / 0.1003+4 V)$

Figure 8 illustrates that, under this assumption, the optimal supervision probability and the optimal rentseeking probability of maximizing the revenue of government agents decrease as the salary of government agents increases. As $\left(p_{z}^{*}\right)^{\prime}=\left(-2.28 /(0.1003+4 V)^{2}\right), \quad\left(q^{*}\right)^{\prime}=$ $\left(-20 /(2.7912+20 V)^{2}\right), \quad$ and $\left|-20 /(2.7912+20 V)^{2}\right|$ $<\left|-2.28 /(0.1003+4 V)^{2}\right|$, the change in government agents' salary has an evident impact on the optimal supervision probability. In the case of high salary, government agents less likely accept enterprises' rent-seeking, and the supervision departments can relax the supervision appropriately, which provides an empirical basis for maintaining honesty with high salary.

Object 6: Influence of supervision $K$ costs on $q^{*}$

Constraint conditions: $q^{*}$ is mainly distributed between $(0,1)$, and $K \leq 0.06$

Optimal rent-seeking probability: $q^{*}=(1 / 0.0786) K$

As shown in Figure 9, the higher the supervision cost, the higher the optimal rent-seeking probability. When the supervision cost is high, supervision departments likely choose inaction, whereas private enterprises and government agents can take the opportunity to seek rent and additional benefits. If the supervision cost is reduced, then the rent-seeking probability also decreases because, with low supervision cost, the revenue of supervision departments can increase, and the possibility of inspection increases. Private enterprises and government agents can only abide by the law.

\section{Research Conclusion and Policy Recommendations}

By constructing an emergency rescue service of government regulators, private enterprises, and government agents of a tripartite rent-seeking game model on the basis of the analysis of data simulation, this study has obtained the following conclusions: (1) When the enterprise rent-seeking cost is large, government agents from private companies likely choose rent-seeking, where supervision departments should strengthen the supervision over government agents at this time; when the rent income is large, private sectors bribe government agents for additional benefits, in which case the supervision focus should be on private enterprises. (2) Project success rate is an important factor for private enterprises to choose whether to seek rent or not. Considering the complexity of the public welfare of emergency rescue services, the government should provide the corresponding help to private enterprises to ensure the success of project operation and maximize public interests while implementing third-party supervision. (3) When the verification success rate of the supervision department is high, the supervision can relax the supervision appropriately. A high verification success rate can effectively reduce the optimal rent-seeking probability and the optimal supervision probability. At this time, the rent-seeking income of the government and enterprises is greatly reduced, and the rentseeking behavior is also restricted; thus the supervision department can conduct random inspection. However, when the verification success rate of the supervision department is low or zero, the supervision is ineffective. At this time, the public and online media should actively participate in the supervision through multiple channels. (4) When the punishment intensity for the government and enterprises is relatively large and the salary of government agents is relatively high, supervision departments can also relax the supervision appropriately. Under such circumstances, if government agents and private enterprises choose to seek rent, then they will be severely punished once they are caught. Rational governments and enterprises can reduce the probability of seeking rent to protect their interests. (5) The level of supervision cost influences that of optimal rentseeking probability. To reduce the occurrence of rentseeking behavior, supervision departments should improve the supervision channel and the efficiency of supervision to reduce the supervision cost.

Based on the conclusions above, this study proposes the following policy suggestions for the PPP projects of an emergency rescue service:

(1) Improve the supervision mechanism and management system. Many loopholes exist in the system of our country in the transition period, and the unsound legal norms cannot restrain the privileges of some government officials, leading to rampant rentseeking activities. Therefore, we should timely revise and introduce laws that are suitable for PPP development; set up supervision agencies at provincial, municipal, and local levels; and regulate the cooperation between the government and enterprises. Moreover, supervision departments can conduct inspections at different stages of PPP projects, such as focusing on the competitive links in the bidding and tendering stage and the service quality in the operation stage, to improve the supervision efficiency. 


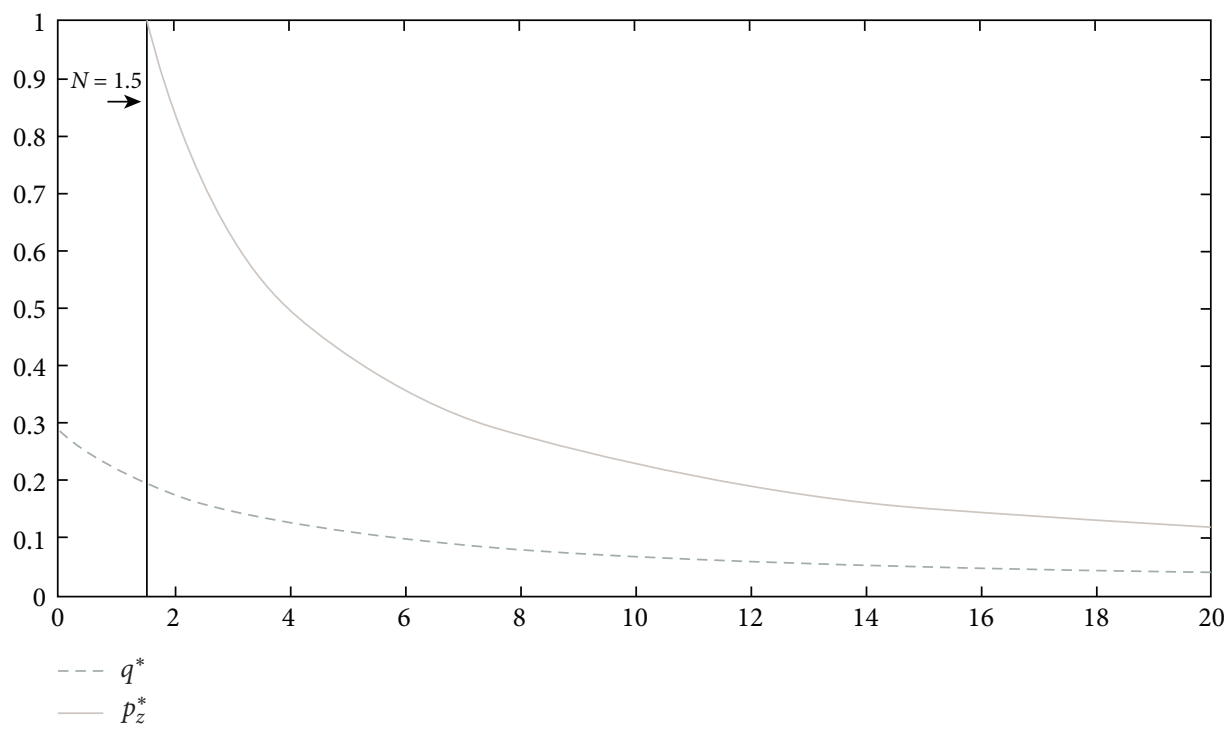

FIGURE 7: Simulation diagram of the influence of punishment intensity $N$ on optimal rent-seeking probability $q^{*}$ and optimal supervision probability $p_{z}^{*}$.

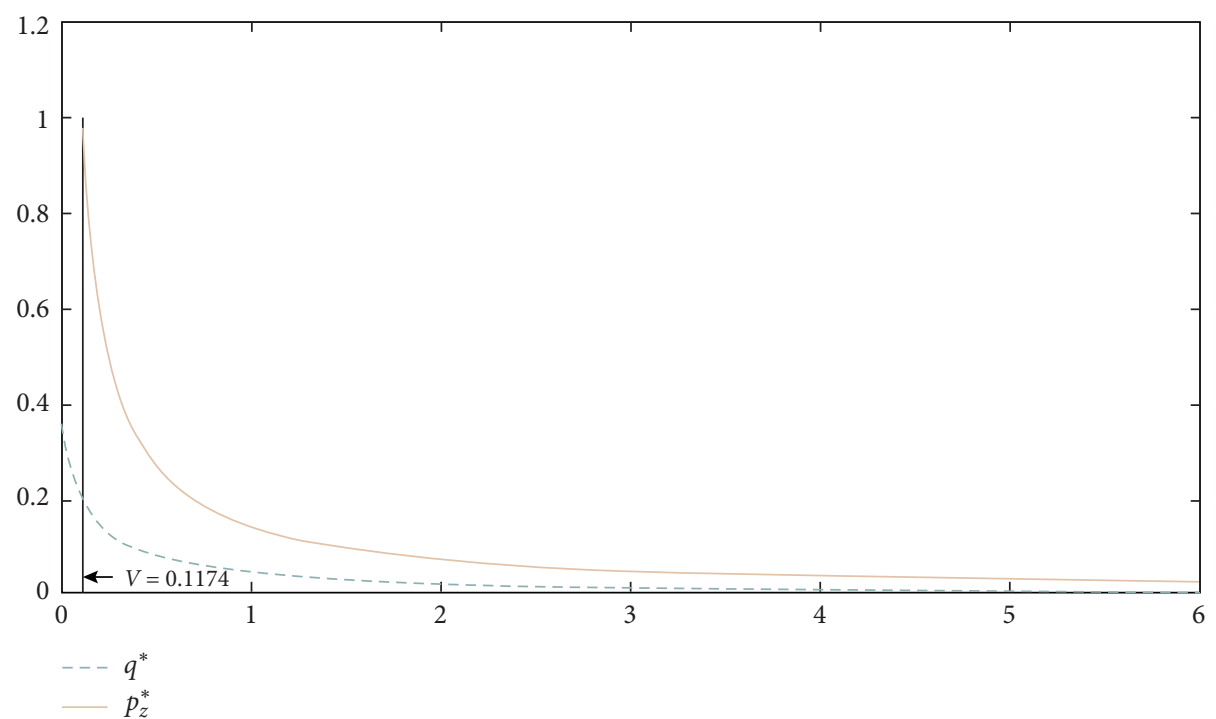

FIGURE 8: Simulation diagram of the influence of government agent salary on optimal rent-seeking probability and optimal supervision probability.

(2) Introduce a competition mechanism to improve the degree of information disclosure. The effective measure to prevent rent-seeking is public bidding by the government, and many private enterprises fairly receive the right to cooperate with PPP projects through competition. The fierce competition among private enterprises can lead to the increase in rentseeking cost, and when the cost is not less than the expected benefits brought by PPP projects, rational private enterprises do not choose rent-seeking. Under public bidding, government agents have a difficult time exercising their rights privately to obtain illegitimate benefits, and the rent-seeking space can be greatly reduced. At the same time of open competitive bidding, the government should do a good job in information disclosure and improve the information feedback of various channels to reduce the supervision cost incurred by the collection of information during the inspection by supervision departments. We can publicize the information and progress of PPP projects and other procedures, open a hotline for public complaints, and form a multifaceted supervision by supervision department, the public, and online media. In this way, rent-seeking becomes further difficult for government agents and private enterprises.

(3) A high salary prevents corruption. Government agents choose to cooperate with private enterprises 


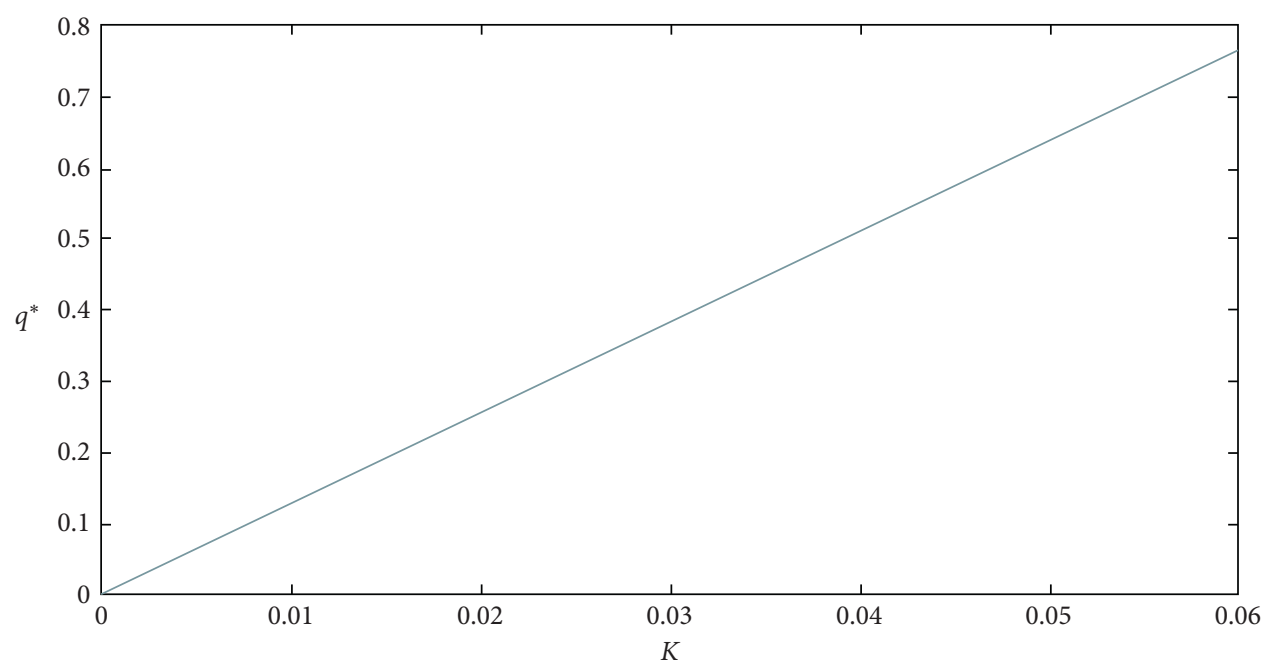

FIGURE 9: Simulation diagram of the influence of supervision cost on the optimal rent-seeking probability.

for rent-seeking to obtain benefits beyond their salaries. If the government provides sufficiently high salaries and bonuses to agents, they may resist the temptation of rent-seeking. However, people's desire is endless. Providing high salaries results in heavy rent-seeking cost. Otherwise, government agents can still choose rent-seeking cooperation speculatively.

(4) Establish and improve the reward and punishment mechanism. Government supervision departments should fulfill their duties, strengthen their inspection of PPP projects, and take severe punishment measures once they discover the rentseeking behavior of government agents and private enterprises. On the one hand, illegal private enterprises can collect a high fine. On the other hand, they can report criticism on the information disclosure platform. Thus, their good corporate image can be affected to an extent. Government agents are subject to various punishments, including economic penalties and administrative sanctions, depending on the seriousness of the circumstances, wherein their reputation, prospects, and materials can be affected. These agents can also deeply reflect on the adverse consequences of their actions, along with government departments to achieve clear rewards and penalties. In the process of an emergency rescue service, a large amount of rescue costs is generated. In the process of disaster relief, private enterprises must bear numerous operational risks, transportation costs, storage costs of relief materials, and other operating costs. Although participating in disaster relief operations can help enterprises establish a good public social image, such participation rarely brings benefits and profits to enterprises. Therefore, the government should take some incentive measures to mobilize the enthusiasm of social capital to participate in PPP projects. For example, the government should clarify the conditions of government compensation in the early stage of the project by means of phased subsidies. Moreover, the government should provide appropriate financial compensation and additional incentives to enterprises that perform well in emergency rescue to motivate them to do a good job in rescue services.

Although this study has obtained some meaningful conclusions, it still has the following shortcomings. No literature exists to refer to for the data simulation, supervision cost, and supervision success rate conducted in this study. Determining the scope of high supervision rate or high rent-seeking rate is also impossible. Thus, only the comparison between large and small data can be conducted. In future research, data analysis can be carried out based on examples to obtain more scientific conclusions.

\section{Data Availability}

The annual data used to support the findings of this study have been deposited in China Industry Statistical Yearbook (ISBN: 978-7-5037-7673-1).

\section{Conflicts of Interest}

The authors declare that they have no conflicts of interest.

\section{Acknowledgments}

The authors acknowledge the financial support from the National Natural Science Foundation of China (no. 71371100) and Major Project of Philosophy and Social Science Research in Jiangsu Province (2017ZDAXM005). This work are also funded by the Six Talent Peaks Project in Jiangsu Province (2016) and the 333 Talent Project in Jiangsu Province (2018). 


\section{References}

[1] Z. Nivolianitou and B. Synodinou, "Towards emergency management of natural disasters and critical accidents: the Greek experience," Journal of Environmental Management, vol. 92, no. 10, pp. 2657-2665, 2011.

[2] A. M. Cordero-Reyes, I. Palacios, D. Ramia et al., "Natural disaster management: experience of an academic institution after a 7.8 magnitude earthquake in Ecuador," Public Health, vol. 144, no. 144, pp. 134-141, 2017.

[3] M. A. Cole, R. J. R. Elliott, T. Okubo, and E. Strobl, "Predisaster planning and post-disaster aid: examining the impact of the great East Japan Earthquake," International Journal of Disaster Risk Reduction, vol. 21, no. 21, pp. 291-302, 2017.

[4] B. K. Paul, B. Acharya, and K. Ghimire, "Effectiveness of earthquakes relief efforts in Nepal: opinions of the survivors," Natural Hazards, vol. 85, pp. 1169-1188, 2017.

[5] A. D. B. Cook, M. Shrestha, and Z. B. Zin Bo Htet, "An assessment of international emergency disaster response to the 2015 Nepal earthquakes," International Journal of Disaster Risk Reduction, vol. 31, no. 31, pp. 535-547, 2018.

[6] M. Ali, C. Miyoshi, and H. Ushijima, "Emergency medical services in Islamabad, Pakistan: a public-private partnership," Public Health, vol. 120, no. 1, pp. 50-57, 2005.

[7] J. Hallikainen, M. Castrén, and A. Saari, "Emergency medical services in rural areas of Finland," Notfall, vol. 17, no. 3, pp. 199-201, 2014.

[8] Q. Guo and J. Fan, "The new reflection on the establishment of China's emergency rescue power system," in Proceedings of the 2011 2nd IEEE International Conference on Emergency Management and Management Sciences, pp. 447-450, IEEE, Beijing, China, August 2011.

[9] C. Shan, "Vigorously developing the emergency industry," China Emergency Management, vol. 5, no. 3, pp. 17-19, 2011.

[10] G. Zhang, J. Wang, and P. Wang, "Research on the construction of emergency rescue social service system for mountaineering in China," Safety and Environmental Engineering, vol. 20, no. 6, pp. 137-140, 2013.

[11] G. Chen, "Socialized emergency rescue team construction and service mode exploration," China Production Safety Science and Technology, vol. 12, no. 2, pp. 9-14, 2016.

[12] J. Jiang, "How emergency services grow into a new potential for economic development," New Economy Guide, vol. 17, no. 1, pp. 18-22, 2017.

[13] Q. Wu, N. Liu, and K. Tang, "A study of the influence of public-private partnership on rescue efficiency in humanitarian supply chain," in Proceedings of the 2010 IEEE International Conference on Emergency Management and Management Sciences, pp. 114-117, IEEE, Beijing, China, August 2010.

[14] H. Zhang and X. Tong, "Structural changes and theoretical generalization of emergency management in China," Chinese Social Sciences, vol. 36, no. 3, pp. 58-84, 2015.

[15] Y. Zhao, "Risk factors of PPP project failure in China and countermeasures," Research on Local Finance, vol. 12, no. 6, pp. 52-56, 2015.

[16] A. P. C. Chan, J. F. Y. Yeung, C. C. P. Yu, S. Q. Wang, and Y. Ke, "Empirical study of risk assessment and allocation of public-private partnership projects in China," Journal of Management in Engineering, vol. 27, no. 3, pp. 136-148, 2011.

[17] Y. Ke, S. Wang, A. P. C. Chan, and P. T. I. Lam, "Preferred risk allocation in China's public-private partnership (PPP) projects," International Journal of Project Management, vol. 28, no. 5, pp. 482-492, 2010.
[18] A. Ng and M. Loosemore, "Risk allocation in the private provision of public infrastructure," International Journal of Project Management, vol. 25, no. 1, pp. 66-76, 2007.

[19] Y. Xu, J. F. Y. Yeung, A. P. C. Chan, D. W. M. Chan, S. Q. Wang, and Y. Ke, "Developing a risk assessment model for PPP projects in China-a fuzzy synthetic evaluation approach," Automation in Construction, vol. 19, no. 7, pp. 929-943, 2010.

[20] L. Zhang, X. Sun, and H. Xue, "Identifying critical risks in Sponge City PPP projects using DEMATEL method: a case study of China," Journal of Cleaner Production, vol. 226, pp. 949-958, 2019.

[21] X. Lu, "Analysis and selection of PPP operation mode based on typical cases--and on the strategic suggestions for promoting cooperation between government and social capital in China," Fiscal Research, vol. 35, no. 11, pp. 14-17, 2014.

[22] S. Wang and T. Liu, "PPP project supervision: domestic and foreign experience and policy suggestions," Research on Local Finance, vol. 11, no. 9, pp. 7-12, 2014.

[23] H. Chen, X. Huang, and D. Guo, "Rent-seeking game and regulatory countermeasures in public-private partnership (PPP)," Fiscal Research, vol. 35, no. 10, pp. 20-24, 2014.

[24] W. Chen, "Research on independent regulation of PPP model in infrastructure industry," Journal of Shanghai University of Finance and Economics, vol. 17, no. 6, pp. 47-56, 2015.

[25] X. He and X. Wang, "Stability analysis of PPP project operation and government supervision from the perspective of evolutionary game," Journal of Finance and Accounting, vol. 38, no. 2, pp. 17-22, 2017.

[26] Y. Duan, Research on PPP Cooperation Mode of Private Capital Participating in the Development of Emergency Industry, Southwest Jiaotong University, Chengdu, China, 2017. 